\title{
The effect of vibratory stimulus on pain perception during intraoral local anesthesia administration in children: a systematic review and meta-analysis
}

\author{
Sunny Priyatham Tirupathi', Srinitya Rajasekhar ${ }^{2}$ \\ ${ }^{1}$ Department of Pedodontics \& Preventive Dentistry, Malla Reddy Institute of Dental Sciences, Hyderabad Telangana, India \\ ${ }^{2}$ Department of Pedodontics \& Preventive Dentistry, Malla Reddy Dental College for Women, Hyderabad, Telangana, India
}

\begin{abstract}
Background: To evaluate the effectiveness of vibration as a counter-stimulatory measure in reducing subjective pain due to local anesthesia administration in children.

Methods: Electronic databases (PubMed, Ovid SP, Cochrane Central Register of Controlled Trials) were searched until April 2020. Studies were screened by titles and abstracts, followed by full text evaluation of the included studies.

Results: A total of seven studies involving 376 children aged 5-17 years were included in the systematic review and meta-analysis. The meta-analysis compared vibration as a counter-stimulatory measure with no vibration as a comparator. The primary outcome evaluated was pain perception or subjective pain reported by the child. The secondary outcome evaluated was objective pain evaluated in each study. The pooled mean difference favored vibration to be effective for the first outcome.

Conclusion: Within the limits of this systematic review, low quality evidence suggests that vibration as a counter-stimulatory measure is effective in reducing the subjective pain reported by children during local anesthesia administration.
\end{abstract}

Keywords: Children; Counter Stimulation; Dental Care; Injections; Vibration.

This is an Open Access article distributed under the terms of the Creative Commons Attribution Non-Commercial License (http://creativecommons.org/licenses/by-nc/4.0/) which permits unrestricted non-commercial use, distribution, and reproduction in any medium, provided the original work is properly cited.

\section{INTRODUCTION}

Local anesthesia administration is one of the feared yet most important factors in improving the success of any treatment in pediatric dentistry [1]. Effective pain control during the administration of dental injections is very important as it reinforces the trust of the child in the dentist, thereby paving the path for a smooth treatment delivery. Pain perceived during local anesthesia administration in children is mitigated by many methods, such as application of topical anesthetics [2], use of a camouflage syringe [3,4], active distraction methods such as deep breathing [5], WITAUL (writing in the air using legs) [6], eye movement distraction [7], usage of audiovisual glasses [8], buffering the local anesthetic solution [9,10], warming the local anesthetic solution [11], and pre-cooling the injection site [12]; these are few measures to reduce pain perception during local anesthesia administration.

Physical counter-stimulatory measures, such as vibration, are also reported to reduce pain during local anesthesia administration. Pain control due to vibratory stimulus can be explained on the basis of "gate-control"

Received: July 13, 2020 • Revised: October 4, 2020 - Accepted: October 25, 2020

Corresponding Author: Sunny Priyatham Tirupathi, Department of Pedodontics \& Preventive Dentistry, Malla Reddy Institute of Dental Sciences, Hyderabad Telangana, India.

E-mail: dr.priyatham@gmail.com

Copyright(c) 2020 Journal of Dental Anesthesia and Pain Medicine 
theory by Melzak and Wall 1965 [13]. According to this theory, counter-stimulation methods such as vibration or cold can reduce the transmission of pain signals from the periphery to the brain by activating A-beta fibers (non-noxious) whose diameter is larger than A-delta and $\mathrm{C}$ fibers, which are pain-receptive fibers, therefore intercepting the pain signal. This occurs by activating the inhibitory interneuron in the dorsal horn of the spinal cord that acts like a gate, reducing the pain information transmitted to the brain [13].

Vibratory stimuli for intraoral dental injection-related procedures were obtained by various methods such as direct manual stimulation using cotton roll vibration [14], specialized attachment devices that fit on the syringe (SMV- Syringe Micro Vibrator) [15,16], and intraoral vibratory devices such as Dental Vibe ${ }^{\circledR}$ [17]. Studies reported diversified outcomes with the use of vibration as a counter-stimulatory method to reduce dental injection-related pain in children - positive [18-22] and no significant difference $[23,24]$. On the contrary, few studies have reported that vibration sensation during intraoral local anesthesia administration is perceived as discomfort by the child [23]. To the best of our knowledge, no systematic review has evaluated vibratory stimulus for intraoral needle prick pain in children.

The purpose of this systematic review and metaanalysis was to investigate the effect of vibration as a counter-stimulatory method on subjective pain (pain perception) and pain reaction during dental local anesthesia administration in children.

\section{METHODS}

Protocol and registration: This study is registered under Prospero [CRD42020180952] and is reported according to the PRISMA guidelines.

Eligibility criteria: The search strategy was conducted using the Population, Intervention, Comparison, and Outcome (PICO) framework, based on the following question: "Does vibration have any influence on pain perception and pain reaction during local anesthesia administration in children." The PICO search strategy of the systematic review was: $(\mathrm{P})$ patient: children between 3 to 17 years; (I) intervention: using intraoral vibration at the injection site during local anesthesia administration (infiltration, block, maxilla, or mandible); (C) comparison: no vibration. (O) Outcome of interest: pain perception

Children aged between 3 and 17 years who were undergoing local anesthesia (supraperiosteal or block injections) were selected. The intervention consisted of a vibratory stimulus using any mechanical device intra-orally, which can induce vibration during needle prick and during the actual administration of local anesthesia. The control group consisted of patients who did not received vibratory stimulus, or who received traditional syringes or patients who received any other intervention other than vibration. Electronic searches were performed in three databases: PubMed, Ovid SP, and Cochrane. The search was conducted until April 2020. Only articles published in English are included. The search was based on a pre-specified question using relevant MeSH terms. ("vibration") AND ("dental") AND ("child").

Eligibility criteria: Randomized controlled clinical trials related to intraoral vibro-tactile devices and pain perception during local anesthesia administration in children were included. Non-randomized studies or non-controlled clinical trials, comparative studies, case reports, narrative reviews, and systematic reviews and articles that could not be translated to English were excluded. Studies on extra-oral vibratory devices, external vibratory devices that are attached to the cartridge (Vibraject), and studies on manual stimulation/vibration

\begin{tabular}{|c|c|c|}
\hline Sno & Excluded articles & Reasons for Exclusion \\
\hline 1. & Bilsin 2020 & Extra-oral vibration was used \\
\hline 2. & Hedge 2019 & Extra-oral vibration was used \\
\hline 3. & Alanazi 2019 & Extra-oral vibration was used \\
\hline 4. & Bagherian 2016 & Manual vibration with cotton-roll \\
\hline 5. & Roeber 2011 & Vibra-Ject (external attachment was used) \\
\hline 6. & Aminabadi 2008 & Manual vibration with finger \\
\hline
\end{tabular}




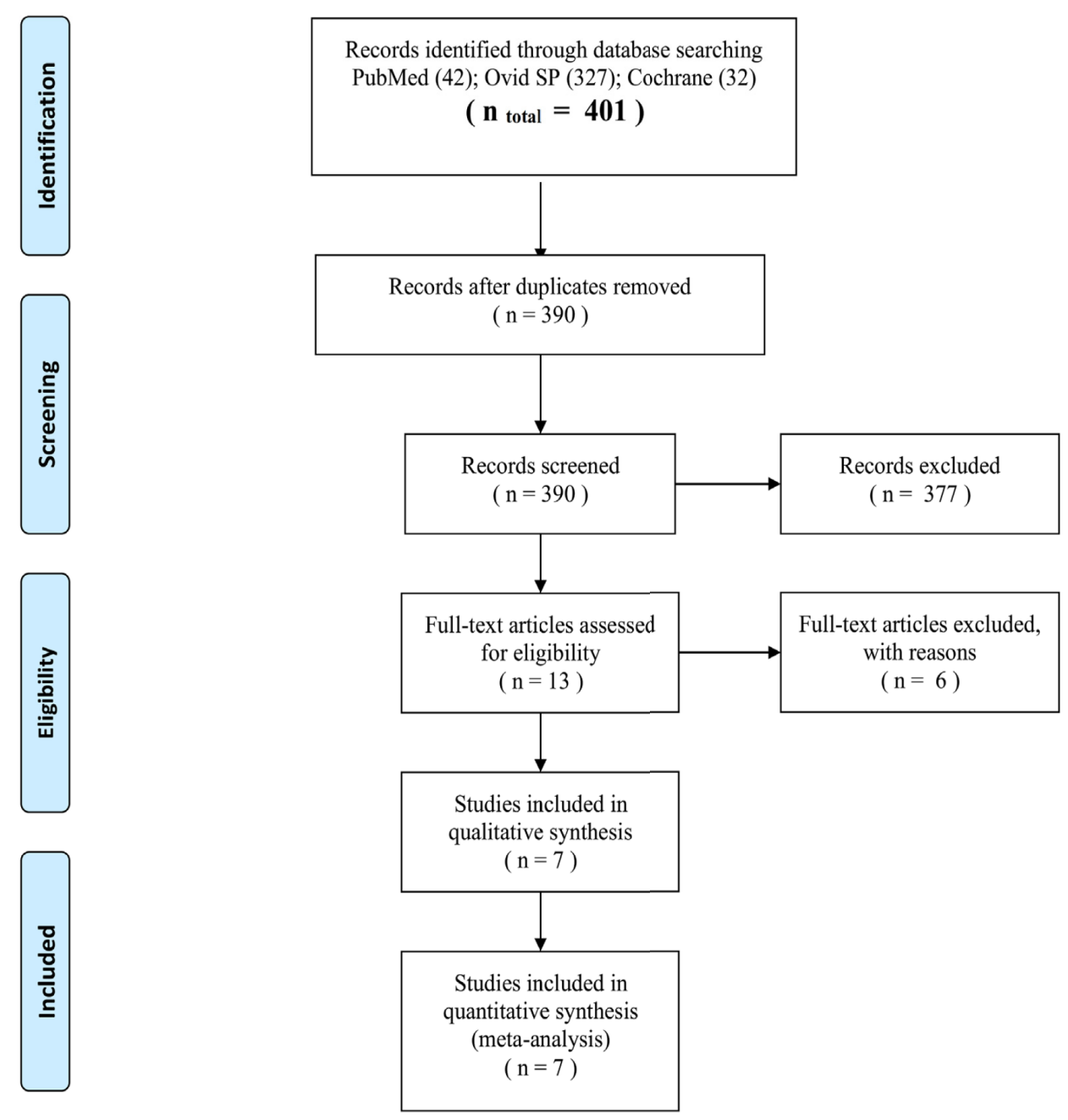

Fig. 1. Flowchart.

were also excluded. Initially, studies were screened based on their titles and abstracts and were imported to Zotero (www.zotero.org) from all databases, and exclusion of duplicates was performed. Potential articles were then included for full review. Data extraction and data analysis were performed by two independent reviewers and recorded on Excel. The data form contained information regarding author names and year of publication, study design, number of participants, age, intervention, control, and outcome. The primary outcome measure sought for was "Pain perception" i.e, self-reported pain score of the child. Secondary outcome included "Pain reaction" i.e, pain observed and scored by the operator. Means and standard deviations were collected from individual studies.
Data synthesis: A meta-analysis was performed to address the review question. Combined results were presented as a pooled mean difference, which was estimated using fixed and random-effect models. A statistical significance level of $5 \%$ was adopted. In the event of heterogeneity (chi-square $\mathrm{P}<0.05$ or $\mathrm{I}^{2}$ index greater than $50 \%$ ), the random-effect model was preferred [25]. Studies adopting crossover design were included twice, in this type of study, the same group of children was part of the control and intervention groups at different times generating two estimates. The outcome analysis was further classified based on the type of instrument (pain score criteria) used for evaluation.

Risk of bias assessment: A methodological quality assessment of the included articles was conducted 
Table 2. Characteristics of included studies

\begin{tabular}{|c|c|c|c|c|c|c|c|c|c|c|}
\hline $\begin{array}{l}\text { S. } \\
\text { No. }\end{array}$ & Author-year & Study design & $\begin{array}{c}\text { Sample } \\
\text { characteristics }\end{array}$ & $\begin{array}{l}\text { Type of } \\
\text { injection }\end{array}$ & $\begin{array}{l}\text { Gauge of manual } \\
\text { syringe used }\end{array}$ & $\begin{array}{c}\text { Topical } \\
\text { anesthesia }\end{array}$ & $\begin{array}{c}\text { Intervention } \\
\text { characteristic and } \\
\text { comparison groups }\end{array}$ & $\begin{array}{l}\text { Vibration } \\
\text { instrument }\end{array}$ & $\begin{array}{l}\text { Measuring } \\
\text { Scales }\end{array}$ & Outcomes \\
\hline 1 & $\begin{array}{l}\text { Hassanein } \\
2020 \text { [20] }\end{array}$ & $\begin{array}{l}\text { Split mouth } \\
\text { cross-over } \\
\text { randomized } \\
\text { controlled } \\
\text { clinical trial }\end{array}$ & $\begin{array}{l}60 \text { children, aged } 5 \text { to } 7 \\
\text { years }\end{array}$ & IANB & 27-gauge needle & $20 \%$ benzocaine & $\begin{array}{l}60 \text { - Dental vibe } \\
60 \text { - Traditional syringe }\end{array}$ & Dental Vibe & $\begin{array}{l}\text { WB- FPR } \\
\text { Scale } \\
\text { FLACC scale. }\end{array}$ & $\begin{array}{l}\text { Vibration } \\
\text { better. }\end{array}$ \\
\hline 2 & $\begin{array}{l}\text { Tung } 2018 \\
{[21]}\end{array}$ & $\begin{array}{l}\text { Randomized } \\
\text { control trial }\end{array}$ & $\begin{array}{l}\text { Total } 150 \text { children aged } \\
\text { 7-14 years were divided } \\
\text { into three groups } \\
\text { G1: No vibration- } 50 \\
\text { children } \\
\text { G2: Manual stimulation- } \\
50 \text { children } \\
\text { G3: Dental Vibe- } 50 \\
\text { children. }\end{array}$ & $\begin{array}{l}\text { IANB, long } \\
\text { buccal } \\
\text { injections, } \\
\text { maxillary } \\
\text { infiltration } \\
\text { injections }\end{array}$ & $\begin{array}{l}\text { 27-gauge needle } \\
\text { for IANB and } \\
\text { 30-gauge needle } \\
\text { for maxillary } \\
\text { infiltrations }\end{array}$ & $\begin{array}{l}20 \% \text { benzocaine } \\
\text { gel. }\end{array}$ & $\begin{array}{l}50 \text { - G1: No vibration } \\
50 \text { - G3: Dental Vibe }\end{array}$ & Dental Vibe & $\begin{array}{l}\text { WB- FPR } \\
\text { Scale } \\
\text { Pulse rate. }\end{array}$ & $\begin{array}{l}\text { Vibration } \\
\text { better }\end{array}$ \\
\hline 3 & $\begin{array}{l}\text { Raslan } 2018 \\
\text { [23] }\end{array}$ & $\begin{array}{l}\text { Split mouth } \\
\text { cross-over } \\
\text { randomized } \\
\text { controlled } \\
\text { clinical trial }\end{array}$ & $\begin{array}{l}40 \text { children, aged } 6 \text { to } \\
12 \text { years }\end{array}$ & $\begin{array}{l}\text { IANB, } \\
\text { buccal and } \\
\text { palatal } \\
\text { infiltration }\end{array}$ & 27-gauge needle & $\begin{array}{l}\text { Topical } \\
\text { anesthesia was } \\
\text { not used. }\end{array}$ & $\begin{array}{l}40 \text { - Dental vibe } \\
40 \text { - Traditional syringe }\end{array}$ & Dental Vibe & $\begin{array}{l}\text { WB- FPR } \\
\text { Scale } \\
\text { FLACC scale }\end{array}$ & $\begin{array}{l}\text { No } \\
\text { significant } \\
\text { difference } \\
\text { between } \\
\text { vibration and } \\
\text { control grou }\end{array}$ \\
\hline 4 & $\begin{array}{l}\text { Tandon } \\
2018 \text { [22] }\end{array}$ & $\begin{array}{l}\text { Split mouth } \\
\text { cross-over } \\
\text { randomized } \\
\text { controlled } \\
\text { clinical trial }\end{array}$ & $\begin{array}{l}30 \text { children, aged } 6 \text { to } \\
11 \text { years }\end{array}$ & $\begin{array}{l}\text { IANB, } \\
\text { mandibular } \\
\text { infiltrations }\end{array}$ & 27-gauge needle & Precaine gel & $\begin{array}{l}30 \text { - Vibration } \\
30 \text { - Traditional syringe }\end{array}$ & $\begin{array}{l}\text { Electric } \\
\text { toothbrush } \\
\text { modified. }\end{array}$ & $\begin{array}{l}\text { WB- FPR } \\
\text { Scale } \\
\text { SEM scale }\end{array}$ & $\begin{array}{l}\text { Vibration } \\
\text { better }\end{array}$ \\
\hline 5 & $\begin{array}{l}\text { Shilpapriya } \\
2015 \text { [19] }\end{array}$ & $\begin{array}{l}\text { Split mouth } \\
\text { cross-over } \\
\text { randomized } \\
\text { controlled } \\
\text { clinical trial }\end{array}$ & $\begin{array}{l}30 \text { children, aged } 6 \text { to } \\
12 \text { years }\end{array}$ & $\begin{array}{l}\text { Not } \\
\text { specified }\end{array}$ & 27-gauge needle & Precaine gel & $\begin{array}{l}30 \text { - Dental vibe } \\
30 \text { - Traditional syringe }\end{array}$ & Dental Vibe & $\begin{array}{l}\text { Universal } \\
\text { pain } \\
\text { assessment } \\
\text { tool }\end{array}$ & $\begin{array}{l}\text { Vibration } \\
\text { better }\end{array}$ \\
\hline 6 & $\begin{array}{l}\text { Elbay } 2015 \\
{[24]}\end{array}$ & $\begin{array}{l}\text { Split mouth } \\
\text { cross-over } \\
\text { randomized } \\
\text { controlled } \\
\text { clinical trial }\end{array}$ & $\begin{array}{l}30 \text { children, aged } 6 \text { to } \\
12 \text { years }\end{array}$ & IANB & $\begin{array}{l}27 \text { gauge. } 4 \% \\
\text { articaine with } \\
\text { epinephrine. }\end{array}$ & $\begin{array}{l}\text { Benzocaine 20\% } \\
\text { spray. }\end{array}$ & $\begin{array}{l}60 \text { - Dental vibe } \\
60 \text { - Traditional syringe }\end{array}$ & Dental Vibe & $\begin{array}{l}\text { WB- FPR } \\
\text { Scale } \\
\text { FLACC scale. }\end{array}$ & $\begin{array}{l}\text { No } \\
\text { significant } \\
\text { difference } \\
\text { between } \\
\text { vibration and } \\
\text { control group }\end{array}$ \\
\hline 7 & $\begin{array}{l}\text { Ching } 2014 \\
{[18]}\end{array}$ & $\begin{array}{l}\text { Split mouth } \\
\text { cross-over } \\
\text { randomized } \\
\text { controlled } \\
\text { clinical trial }\end{array}$ & $\begin{array}{l}36 \text { children, aged } 10 \text { to } \\
17 \text { years }\end{array}$ & $\begin{array}{l}\text { Infiltration } \\
\text { injections in } \\
\text { both jaws }\end{array}$ & $\begin{array}{l}\text { 30-gauge } \\
\text { extra-short } \\
\text { needle with } 2 \% \\
\text { lidocaine } \\
\text { containing } \\
\text { 1:100,000 } \\
\text { epinephrine }\end{array}$ & $20 \%$ benzocaine & $\begin{array}{l}36 \text { - Dental vibe } \\
36 \text { - Traditional syringe }\end{array}$ & Dental Vibe & $\begin{array}{l}\text { WB- FPR } \\
\text { Scale }\end{array}$ & $\begin{array}{l}\text { Vibration } \\
\text { better }\end{array}$ \\
\hline
\end{tabular}

*Abbreviations used in this table: FLACC, Face Legs Activity Cry and Consolability Scale; WB-FPR, Wong-Baker Faces Pain Rating; SEM, Sound eye motor; G1, group 1; G2, group 2; G3, group 3.

independently by two review team members using the Cochrane Collaboration's criteria. The quality of all selected trials was assessed for risk of bias under seven domains: sequence generation, allocation concealment, blinding of participants and personnel, blinding of outcome assessment, completeness of outcome data, selective reporting of outcomes, and other sources of bias. Studies with seven domains of low bias risk were classified into a low risk of bias group. Studies with one or more domains of high bias risk were categorized as 


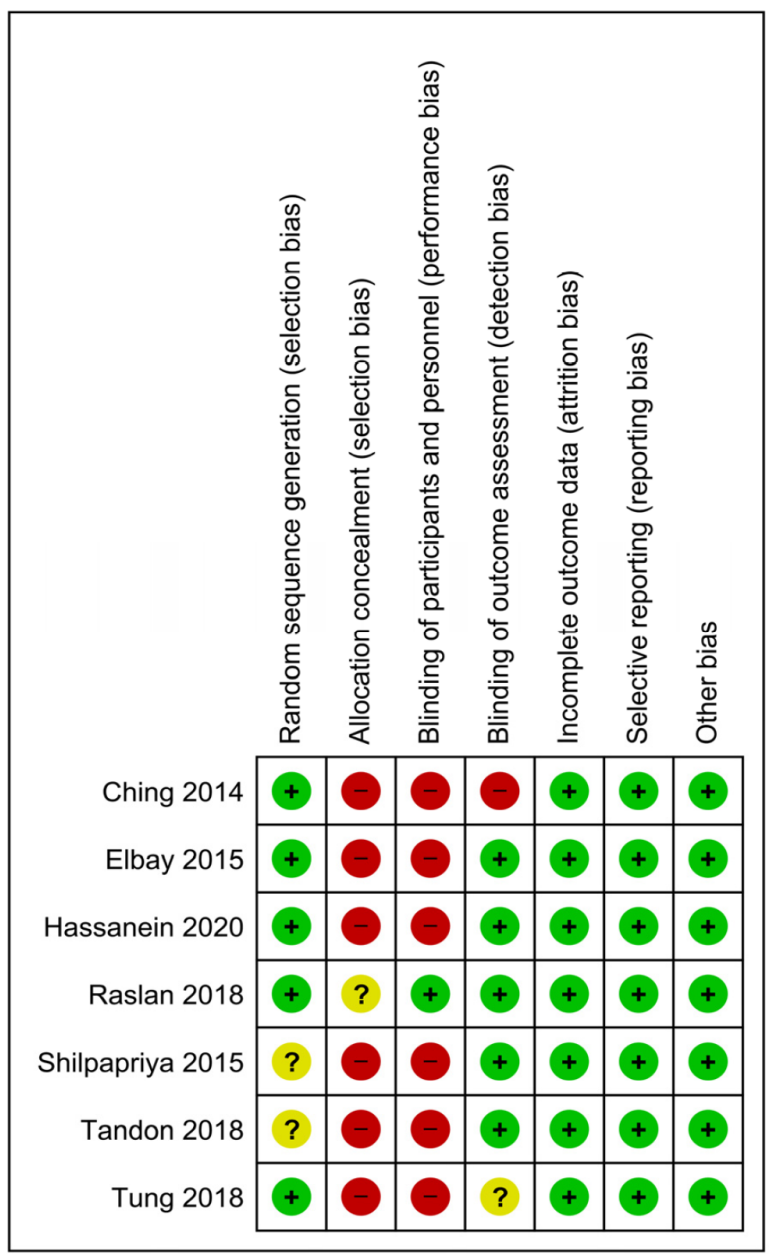

Fig. 2. Risk of bias of all the included studies.

having a high risk of bias; otherwise, the study was categorized as having an unclear risk of bias.

\section{RESULTS}

From all the databases, 401 records were found, of which 11 were duplicates. After removing duplicate articles, 390 records were screened by title and abstract. The full text of the 13 potentially relevant papers was evaluated [14,16,18-24,26-29] and six studies were excluded [14,16,26-29]. Reasons for exclusion are given in Table 1. Consequently, seven studies were included in this systematic review and meta-analysis. All the studies were based on randomized clinical trials, and no case-control studies were found. A flowchart of the search results is presented in Fig. 1.

Characteristics of included studies: The characteristics of the included studies are shown in Table 2. Among these seven studies published between 2014 and 2020, six studies had a crossover design [18-20,22-24], and one study had a randomized controlled design [21].

In total, 376 children aged 5-17 years received different dental injections with or without vibration. All seven included studies evaluated pain perception; among them, six studies [18,20-24], used the Wong-Baker FACES pain rating (WB-FPR) scale, and one study used a universal pain rating scale [19].

Only five studies among the seven evaluated pain reactions; three studies measured pain reaction using the face, legs, activity, cry, consolability (FLACC) scale [20, $23,24]$, one study evaluated pulse rate [21], and another study used the sound, eye, motor (SEM) score [22].

Risk of bias: Risk of bias (Fig. 2) was evaluated according to the Cochrane guidelines. Randomization was mentioned in most of the studies $(\mathrm{n}=5)$. Blinding of participants was not possible with these studies as vibration can be felt by the children. Blinding of outcome assessment was done only in four studies. Most of the studies $(n=7)$ presented a low risk of bias for incomplete outcome data (attrition bias) and selective reporting (bias reporting). All trials were free from other biases.

Effects of vibration interventions on pain perception during dental local anesthesia administration in children (primary outcome): Pain perception in all the included studies was evaluated using the WB-FPR scale, except in one study that used the universal pain scale [19]. In the overall pooled result, a significant reduction in self-reported pain scores by the child was found to be associated with the use of vibration during local anesthesia administration (Standard mean difference -0.99 ; $95 \%$ confidence interval [-1.64 - -0.34]; [Fig. 3])

Effects of vibration interventions on pain reaction (secondary outcome): It was not possible to compare pain reactions in all the studies, as only a few studies reported pain reactions (objective pain). Three studies used the FLACC scale, one study used the SEM scale, one 


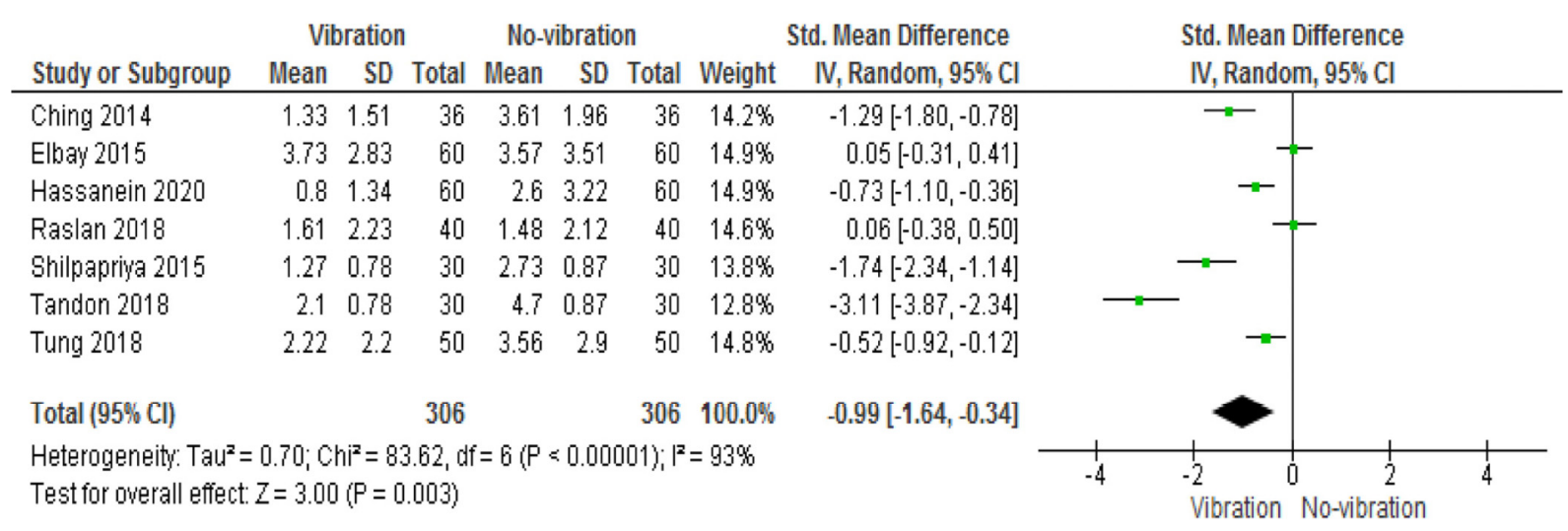

Fig. 3. Pain perception with and without vibration.

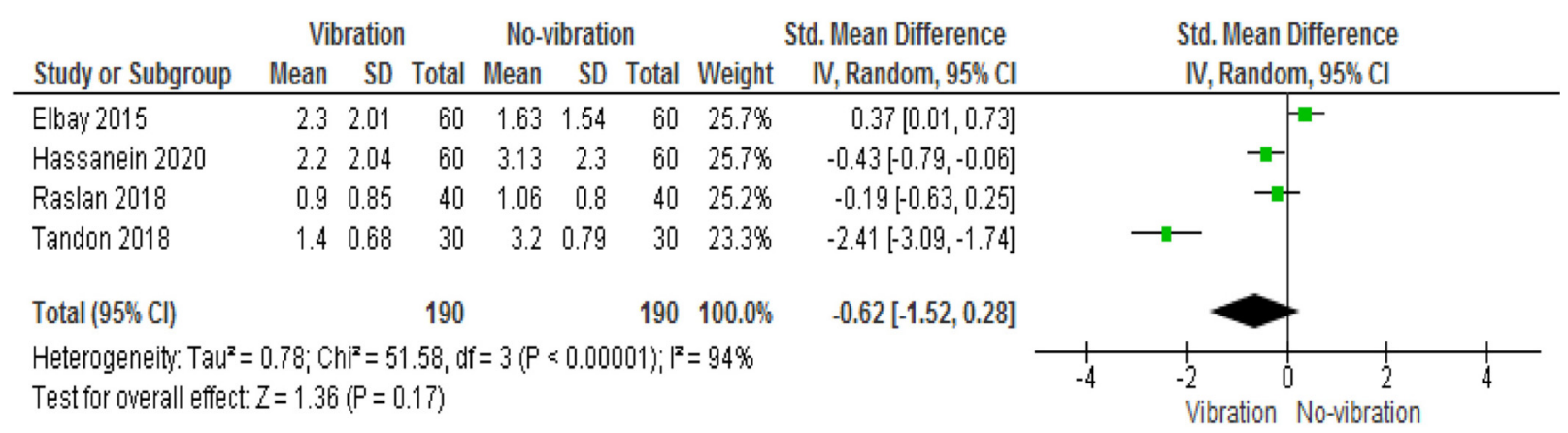

Fig. 4. Pain reaction with and without vibration.

recorded the pulse rate, and two other studies did not measure any pain reaction. In the overall pooled estimate of four studies, no significant difference in the pain reaction between the vibration and control group was observed. (Standard mean difference -0.62; $95 \%$ confidence interval [-1.52 - -0.28$]$; [Fig. 4])

\section{DISCUSSION}

A total of seven studies were included for the final qualitative analysis, most of the studies $(n=6)$ followed a randomized crossover design [18-20,22-24]; only one study followed a randomized control design [21]. The ages of children in the included studies ranged from 5 to 17 years.

The type of intraoral injection varied across the included studies. The effect of vibratory stimulus was tested on the inferior alveolar nerve block (IANB) in most of the studies $(n=5)$ [20-24]. Infiltrations were tested in the study by Ching et al. [18], and the type of injection was not specified in the study by Shilpapriya et al. [19]. Most of the studies reported the use of 27-gauge needles [19-24], except for a few studies that used 30-gauge needles $[18,21]$. Topical anesthesia was used in all the studies $(n=6)[18-22,24]$, except the study by Raslan et al. [23]. Primary outcome (pain perception) was evaluated in all seven studies. Secondary objective pain reactions were evaluated in only five studies [20-24].

Self-reported pain scores for intraoral injections were assessed with and without vibration. Self-reported pain scores were evaluated in six studies using the WB-FPR scale; the universal pain scale was used in the study by Shipapriya et al. [19]. In most of the studies, self-reported pain scores were significantly lower in the vibratory counter-stimulation group than in the control group (n = 5) [18-22]. Two studies (Raslan et al, Elbay et al) reported no significant difference between the vibratory 
counter-stimulation group and control group [23,24]. This might be due to the fact that no topical anesthesia was administered before local anesthesia administration in the study by Raslan et al. In addition, very young children perceive vibration as an unpleasant stimulus and subsequently report more pain. The overall pooled data reported significantly lower self-reported pain scores by the child with the use of vibratory counter stimulation during local anesthesia administration (Standard mean difference -0.99 ; 95\% confidence interval [-1.64 -0.34$]$; [Fig. 3]).

Observed pain (operator reported child reaction) was evaluated as a secondary outcome in this systematic review. Qualitative analysis was carried out for only four studies for this secondary outcome. Three studies evaluated the FLACC score $[20,23,24]$ and one study evaluated SEM [22]. The overall pooled data of four studies for secondary outcome report no significant difference in the pain reaction between the vibration and control groups. (Standard mean difference -0.62; 95\% confidence interval [-1.52 - -0.28]; [Fig. 4]).

Summary of evidence: This systematic review investigated the efficiency of vibration as a counter-stimulatory measure for pain reduction during dental local anesthesia administration in children. Significant differences were found in the pooled results for the primary outcome (pain perception) when vibration was used. Lower pain scores were reported when vibration was used as a counterstimulatory method during local anesthesia administration in children.

Limitations of this review: In the included studies, blinding of participants was not possible because vibration can be felt by children. Needle gauge sizes of injections used as a control were not standardized in all included studies. The source of the vibratory stimulus was standardized in all studies (dental vibe), except one study where a modified electric toothbrush was used [14]. The site of local anesthesia administration was not similar in all the studies, few studies evaluated block injections (IANB) only[12,16], and few studies evaluated the combination of infiltrations and block injections. Pain reaction was also not measured in a few studies[10,11, 13]. Subgroup analysis (age, type of injection) was not performed due to limited studies available. As only three studies reported pain reaction scores (FLACC), we were not able to perform a meta-analysis for the same $[12,15$, $16]$.

Strengths of the study: Only randomized control trials were included for this systematic review. Only studies reporting intraoral vibration at the site of local anesthesia administration were evaluated. Studies reporting extra-oral vibration and other vibratory attachments over the cartridge were excluded to improve the quality of reporting evidence. To the best of our knowledge, this is the first systematic review reporting an association between intraoral vibratory stimulus and pain perception during dental local anesthesia administration in children.

\section{Directions for future research:}

1. The effect of vibration during palatal anesthesia administration can be an interesting topic for future research. Vibration as a counter-stimulatory measure can be a tool for reducing pain perceived during local anesthesia administration in children.

2. Combination of vibration with other counterstimulatory methods also can be considered for future research.

\section{Conclusions}

Based on the available results the following conclusions can be made,

1. The use of intraoral vibration as a counterstimulatory measure is effective in reducing the pain perceived by the child during intraoral local anesthesia administration.

2. The risk of bias is high in most studies. Therefore, the quality of evidence is low.

\section{AUTHOR ORGDS:}

Sunnypriyatham tirupathi: https://orcid.org/0000-0002-2593-0090

Srinitya Rajasekhar: https://orcid.org/0000-0002-1498-1618 


\section{AUHOR GOWHIBUIOUS}

Sunnypriyatham tirupathi: Conceptualization, Data curation, Formal analysis, Methodology, Resources, Supervision, Writing - original draft, Writing - review \& editing

Srinitya Rajasekhar: Writing - review \& editing

FUNDING: There is no financial support or sponsorship to declare.

DECLARATION OF INTEREST: There are no conflicts of interest to declare

\section{REFERENCES}

1. van Wijk AJ, Hoogstraten J. Anxiety and pain during dental injections. J Dent 2009; 37: 700-4.

2. Dasarraju RK, Svsg N. Comparative efficacy of three topical anesthetics on 7-11-year-old children: a randomized clinical study. J Dent Anesth Pain Med 2020; 20: 29-37.

3. Ujaoney S, Mamtani M, Thakre T, Tote J, Hazarey V, Hazarey P, et al. Efficacy trial of camouflage syringe to reduce dental fear and anxiety. Eur J Paediatr Dent 2013; 14: $273-8$.

4. Melwani AM, Srinivasan I, Setty JV, D R MK, Pamnani SS, Lalitya D. A clinical comparative study between conventional and camouflaged syringes to evaluate behavior and anxiety in 6-11-year-old children during local anesthesia administration-a novel approach. J Dent Anesth Pain Med 2018; 18: 35-40.

5. Peretz B, Gluck GM. Assessing an active distracting technique for local anesthetic injection in pediatric dental patients: Repeated deep breathing and blowing out air. J Clin Pediatr Dent 1999; 24: 5-8.

6. Kamath PS. A novel distraction technique for pain management during local anesthesia administration in pediatric patients. J Clin Pediatr Dent 2013; 38: 45-7.

7. Tirupathi S, Krishna N, Rajasekhar S, Nuvvula S. Eye movement distraction: a new distraction technique for management of dental anxiety during intraoral local anesthesia administration in children. Int J Clin Pediatr
Dent 2019; 12: 507-9.

8. Liu Y, Gu Z, Wang Y, Wu Q, Chen V, Xu X, et al. Effect of audiovisual distraction on the management of dental anxiety in children: a systematic review. Int J Paediatr Dent 2019; 29: 14-21.

9. Chopra R, Jindal G, Sachdev V, Sandhu M. Double-blind crossover study to compare pain experience during inferior alveolar nerve block administration using buffered two percent lidocaine in children. Pediatr Dent 2016; 38: 25-9.

10. Meincken M, Norman C, Arevalo O, Saman DM, Bejarano T. Anesthesia onset time and injection pain between buffered and unbuffered lidocaine used as local anesthetic for dental care in children. Pediatr Dent 2019; 41: 354-7.

11. Tirupathi SP, Rajasekhar S. Effect of warming local anesthesia solutions before intraoral administration in dentistry: a systematic review. J Dent Anesth Pain Med 2020; 20: 187-94.

12. Tirupathi SP, Rajasekhar S. Effect of precooling on pain during local anesthesia administration in children: a systematic review. J Dent Anesth Pain Med 2020; 20: 119-27.

13. Dickenson AH. Gate control theory of pain stands the test of time. Br J Anaesth 2002; 88: 755-7.

14. Bagherian A, Sheikhfathollahi M. Children's behavioral pain reactions during local anesthetic injection using cotton-roll vibration method compared with routine topical anesthesia: a randomized controlled trial. Dent Res J (Isfahan) 2016; 13: 272-7.

15. Shahidi Bonjar AH. Syringe micro vibrator (smv) a new device being introduced in dentistry to alleviate pain and anxiety of intraoral injections, and a comparative study with a similar device. Ann Surg Innov Res 2011; 5: 1.

16. Roeber B, Wallace DP, Rothe V, Salama F, Allen KD. Evaluation of the effects of the vibraject attachment on pain in children receiving local anesthesia. Pediatr Dent 2011; 33: 46-50.

17. Nasehi A, Bhardwaj S, Kamath AT, Gadicherla S, Pentapati KC. Clinical pain evaluation with intraoral vibration device during local anesthetic injections. J Clin Exp Dent 2015; 7: e23-7.

18. Ching D, Finkelman M, Loo CY. Effect of the dentalvibe 
injection system on pain during local anesthesia injections in adolescent patients. Pediatr Dent 2014; 36: 51-5.

19. Shilpapriya M, Jayanthi M, Reddy VN, Sakthivel R, Selvaraju G, Vijayakumar P. Effectiveness of new vibration delivery system on pain associated with injection of local anesthesia in children. J Indian Soc Pedod Prev Dent 2015; 33: $173-6$.

20. Hassanein PH, Khalil A, Talaat DM. Pain assessment during mandibular nerve block injection with the aid of dental vibe tool in pediatric dental patients: a randomized clinical trial. Quintessence Int 2020; 51: 310-7.

21. Tung J, Carillo C, Udin R, Wilson M, Tanbonliong T. Clinical performance of the dentalvibe ${ }^{\circledR}$ injection system on pain perception during local anesthesia in children. J Dent Child (Chic) 2018; 85: 51-7.

22. Tandon S, Kalia G, Sharma M, Mathur R, Rathore K, Gandhi M. Comparative evaluation of mucosal vibrator with topical anesthetic gel to reduce pain during administration of local anesthesia in pediatric patients: An in vivo study. Int J Clin Pediatr Dent 2018; 11: 261-5.

23. Raslan N, Masri R. A randomized clinical trial to compare pain levels during three types of oral anesthetic injections and the effect of dentalvibe $\left({ }^{R}\right)$ on injection pain in children. Int J Paediatr Dent 2018; 28: 102-10.

24. Elbay M, Şermet Elbay Ü, Yıldırım S, Uğurluel C, Kaya
C, Baydemir C. Comparison of injection pain caused by the dentalvibe injection system versus a traditional syringe for inferior alveolar nerve block anaesthesia in paediatric patients. Eur J Paediatr Dent 2015; 16: 123-8.

25. DerSimonian R, Laird N. Meta-analysis in clinical trials revisited. Contemp Clin Trials 2015; 45: 139-45.

26. Bilsin E, Güngörmüş Z, Güngörmüş $M$. The efficacy of external cooling and vibration on decreasing the pain of local anesthesia injections during dental treatment in children: a randomized controlled study. J Perianesth Nurs 2020; 35: 44-7.

27. Hegde KM, R N, Srinivasan I, D R MK, Melwani A, Radhakrishna S. Effect of vibration during local anesthesia administration on pain, anxiety, and behavior of pediatric patients aged 6-11 years: a crossover split-mouth study. J Dent Anesth Pain Med 2019; 19: 143-9.

28. Aminabadi NA, Farahani RM, Balayi Gajan E. The efficacy of distraction and counterstimulation in the reduction of pain reaction to intraoral injection by pediatric patients. J Contemp Dent Pract 2008; 9: 33-40.

29. Alanazi KJ, Pani S, AlGhanim N. Efficacy of external cold and a vibrating device in reducing discomfort of dental injections in children: a split mouth randomised crossover study. Eur Arch Paediatr Dent 2019; 20: 79-84. 